\title{
OBSERVATION OF NICKEL HYDROXIDE LAYER ON Ni ELECTRODE BY IN SITU ATOMIC FORCE MICROSCOPY
}

\author{
A. Kowal, R. Niewiara, B. Perończyk and J. Haber \\ Institute of Catalysis and Surface Chemistry, Polish Academy of Sciences \\ Niezapominajek, 30-239 Kraków, Poland
}

The layer of nickel hydroxide was formed on the surface of polycrystalline $\mathrm{Ni}$ immersed in $1 \mathrm{M} \mathrm{KOH}$ by cycling the potential in the range between -0.1 and $0.6 \mathrm{~V}$ vs. $\mathrm{Pt}$ in $1 \mathrm{M} \mathrm{KOH}$. The layer thickness of $8.5 \mathrm{~nm}$, estimated by an electrochemical method, corresponded to about 10 monolayers of $\mathrm{Ni}(\mathrm{OH})_{2}$. The changes of thickness of the nickel hydroxide film during the process of its oxidation and reduction were monitored by the use of in situ atomic force microscopy with the tip fixed and the electrode potential scanned between -0.1 and $+0.6 \mathrm{~V}$ at a scan rate of $100 \mathrm{mV} / \mathrm{s}$. The process of oxidation resulted in the film thickness decrease by about $3 \mathrm{~nm}$. This change could be explained as to be due to the removal of a proton from $\mathrm{Ni}(\mathrm{OH})_{2}$ layer.

PACS numbers: $68.35 . B s$

\section{Introduction}

The immersion of metallic nickel in aqueous alkaline solution leads to the formation of the layer of nickel(II) hydroxide. The knowledge of the properties of such layers is important for applications of nickel electrodes in alkaline batteries, in the process of hydrogen evolution, electrochemical syntheses and their use as electrochromic devices.

The most essential problem which appears here is the course of the oxidation/reduction (the charging/discharging) reaction. The mechanism of this reaction is often described as $[1,2]$ :

$$
\mathrm{Ni}(\mathrm{OH})_{2} \rightleftharpoons \mathrm{NiOOH}+\mathrm{H}^{+}+\mathrm{e}^{-}
$$

or

$$
\mathrm{Ni}(\mathrm{OH})_{2}+\mathrm{OH}^{-} \rightleftharpoons \mathrm{NiOOH}+\mathrm{H}_{2} \mathrm{O}+\mathrm{e}^{-} .
$$

The first reaction assumes the diffusion of a proton from the hydroxide layer to the solution and its reaction with $\mathrm{OH}^{-}$ions in the solution. The second one assumes the diffusion of $\mathrm{OH}^{-}$ions from the solution to the hydroxide layer followed by the 
reaction of $\mathrm{OH}^{-}$with a proton within the $\mathrm{Ni}(\mathrm{OH})_{2}$ layer and the formation of water molecule. It can be expected that the process (1) leads to the decrease in the layer thickness during the process of $\mathrm{Ni}(\mathrm{OH})_{2}$ oxidation while the process (2) should be connected with the increase in the layer thickness. Häring and Kötz [3] reported the use of in situ atomic force microscopy (AFM) for measuring the swelling behavior during the oxidation and reduction of nickel hydroxide films electrochemically deposited onto highly oriented pyrolytic graphite. In our paper the nickel hydroxide layer was formed on the surface of polycrystalline nickel immersed in $1 \mathrm{M} \mathrm{KOH}$ by cycling the potential in the range between -0.1 and $0.6 \mathrm{~V}$ vs. Pt in $1 \mathrm{M} \mathrm{KOH}$.

\section{Experimental}

Nickel plates $12 \mathrm{~mm} \times 12 \mathrm{~mm}$ and $2 \mathrm{~mm}$ thick (99.99\% pure) were obtained from Alfa-Johnson Matthey. These were polished with SiC emery paper and with alumina powder down to $0.05 \mu \mathrm{m}$.

Analar grade $\mathrm{KOH}$ and ultra pure water were used.

The electrode was immersed in $1 \mathrm{M} \mathrm{KOH}$ and subjected to repetitive cycles from -0.1 to $0.6 \mathrm{~V}$ vs. $\mathrm{Pt}$ in $1 \mathrm{M} \mathrm{KOH}$ for $1.5 \mathrm{~h}$ at a scan rate of $100 \mathrm{mV} / \mathrm{s}$. A Pt wire was used as the counter electrode. The area of the working electrode was of $0.71 \mathrm{~cm}^{2}$.

The observations of nickel hydroxide layer on a Ni electrode were carried out with the use of Nanoscope E microscope (Digital Instruments, USA) with ECAFM software and NanoProbes Silicon Nitride cantilevers $(0.12 \mathrm{~N} / \mathrm{m})$.

\section{Results}

The topographic image of the electrode surface, after cycling for 1.5 hours taken at the open circuit potential, is shown in Fig. 1. The observed structure is granular; the lateral size of grains and their height are of about $300 \mathrm{~nm}$ and $20 \mathrm{~nm}$, respectively.

The changes of the $\mathrm{Ni}(\mathrm{OH})_{2}$ film thickness were then monitored during the next step of cycling represented by Figs. 2 and 3. In this experiment the tip remained fixed at the image center and the changes in the height of the film ( $z$ direction) were recorded versus time. The resulting image (constant force mode) is shown in Fig. 4 in which the vertical axis represents the time of potential cycling experiment. Comparing the grey scale at this image one can conclude that the layer thickness changes periodically during the experiment. The dark stripes reflect the decrease in the layer thickness which occurs as the result of the film oxidation. The height profile corresponding to this image is shown in Fig. 5.

\section{Discussion and conclusions}

Basing on the data given by Häring and Kötz [3] one can evaluate the charge $Q_{\mathrm{v}}=1060 \mathrm{C} / \mathrm{cm}^{3}$ connected with the oxidation of $\mathrm{Ni}(\mathrm{OH})_{2}$ layer of size $1 \mathrm{~cm} \times 1 \mathrm{~cm}$. By measuring the charge density $Q_{\mathrm{s}}=9 \times 10^{-4} \mathrm{C} / \mathrm{cm}^{2}$ connected with the reaction (1) (Fig. 2) and comparing this value with $Q_{\mathrm{v}}$ we estimated the average thickness of $\mathrm{Ni}(\mathrm{OH})_{2}$ layer as equal to $8.5 \mathrm{~nm}$. Taking into account the $\mathrm{X}$-ray diffraction data [2] we can conclude that such a layer thickness is of the 


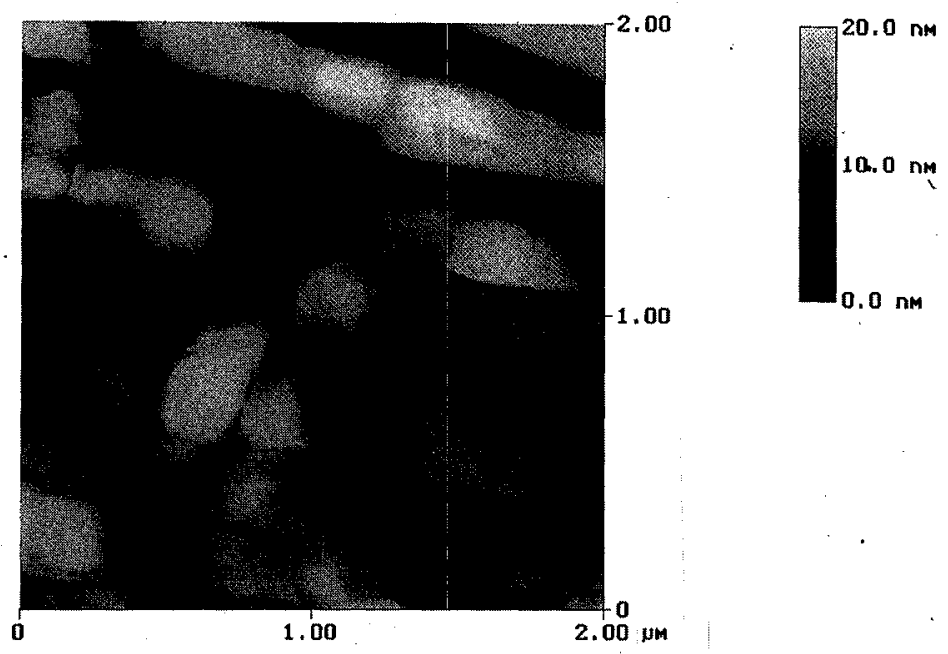

Fig. 1. Topographic AFM image of the $\mathrm{Ni} / \mathrm{Ni}(\mathrm{OH})_{2}$ electrode surface in $1 \mathrm{M} \mathrm{KOH}$ at the open circuit potential after cycling for $1.5 \mathrm{~h}$ in the potential range between -0.1 to $0.6 \mathrm{~V}$ (constant force mode, image without corrections or filtering, image scan frequency $2.04 \mathrm{~Hz})$.

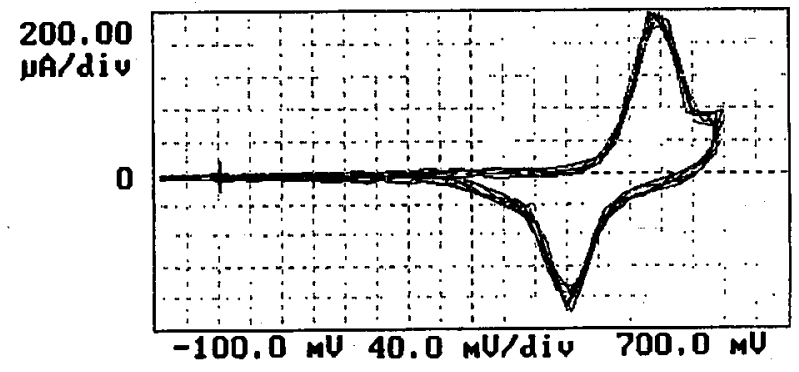

Fig. 2. Cyclic voltammograms of the $\mathrm{Ni} / \mathrm{Ni}(\mathrm{OH})_{2}$ electrode in $1 \mathrm{M} \mathrm{KOH}$ ( 7 cycles after initial cycling for $1.5 \mathrm{~h}$ ); sweep rate $100 \mathrm{mV} / \mathrm{s}$.

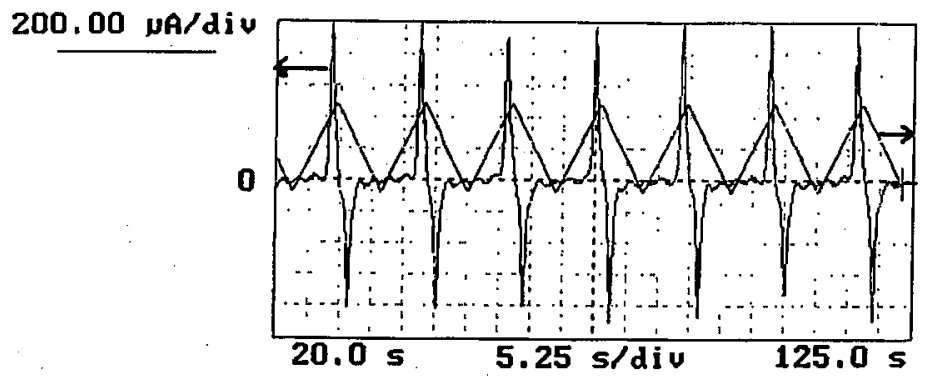

$250.00 \mathrm{mU} / \mathrm{div}$

Fig. 3. Current-time and potential-time dependences for the $\mathrm{Ni} / \mathrm{Ni}(\mathrm{OH})_{2}$ electrode in $1 \mathrm{M} \mathrm{KOH}$ during 7 cycles after initial cycling for $1.5 \mathrm{~h}$. 

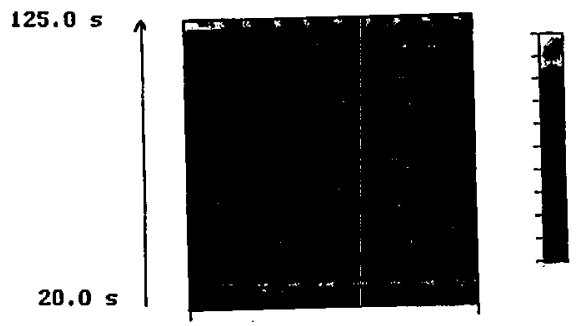

10.0 nu

$5.0 \mathrm{~nm}$

0.0 nm

Fig. 4. AFM image of the $\mathrm{Ni} / \mathrm{Ni}(\mathrm{OH})_{2}$ electrode in $1 \mathrm{M} \mathrm{KOH}$ obtained with the fixed tip during 7 potential cycles between -0.1 and $0.6 \mathrm{~V}$ at a scan rate of $100 \mathrm{mV} / \mathrm{s}$ (image scan frequency $2.47 \mathrm{~Hz}$ ).

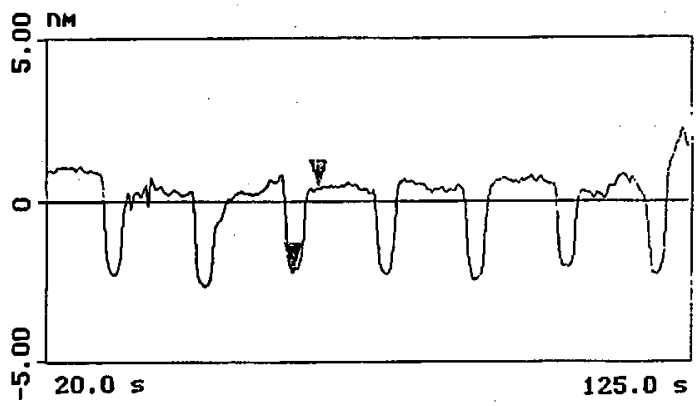

Fig. 5. Height profile corresponding to the AFM image presented in Fig. 4.

order of 10 monolayers. As it can be seen from Figs. 4 and 5, after oxidation the film thickness decreases by about $3 \mathrm{~nm}$. This change is reversed during the process of electrochemical reduction and can be repeated. The reversible thickness change connected with the charging and discharging reactions is of order of $35 \%$ relative to the thickness of the electrochemically prepared $\mathrm{Ni}(\mathrm{OH})_{2}$ film. We can conclude that during the oxidation of $\mathrm{Ni}(\mathrm{OH})_{2}$ film protons diffused from the hydroxide layer to the solution.

\section{References}

[1] M. Bode, K. Dehmelt, J. Witte, Electrochim. Acta 11, 1079 (1966).

[2] J. McBreen, in: Modern Aspects of Electrochemistry, Vol. 21, Eds. R.E. White, J. O'M Bockris, B.E. Conway, Plenum, New York 1990, p. 29.

[3] P. Häring, R. Kötz, J. Electroanal. Chem. 385, 273 (1995). 